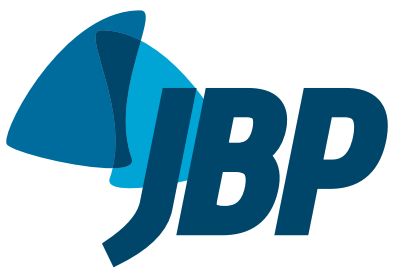

\title{
How to prepare and present a poster at a conference and communicate your research findings effectively
}

\author{
Juliana Carvalho Ferreira ${ }^{1,2, a}$, Cecilia Maria Patino, $0^{1,3, b}$
}

The overall goal of presenting a poster at a conference is to communicate to and receive feedback from your peers who have similar research interests regarding your research findings, as well as to increase your scientific network. To make the most of this opportunity, in an environment where conference attendees are overwhelmed by new information, the presenters of a poster need to communicate their results effectively.

\section{A POSTER IS NOT A MINI MANUSCRIPT}

The most common mistake researchers make when designing and presenting a poster is to treat the poster as if it were a mini manuscript. Remember, the goal is to clearly and quickly communicate research content to attendees who are walking around a large area with many posters, with limited time and attention span to read extensive information.

Successfully communicating your study will rely on attracting attendees to your poster and making it easy for them to grasp key messages. Consider the $10-10$ rule of thumb for poster viewing: attendees look at posters for 10 seconds and from 10 feet ( 3 meters) away. ${ }^{(1,2)}$ During those 10 seconds, if they are attracted to the poster, they might want to read more information. Therefore, your key messages must be written using a large enough font size for people to read it from 3 meters away, and the

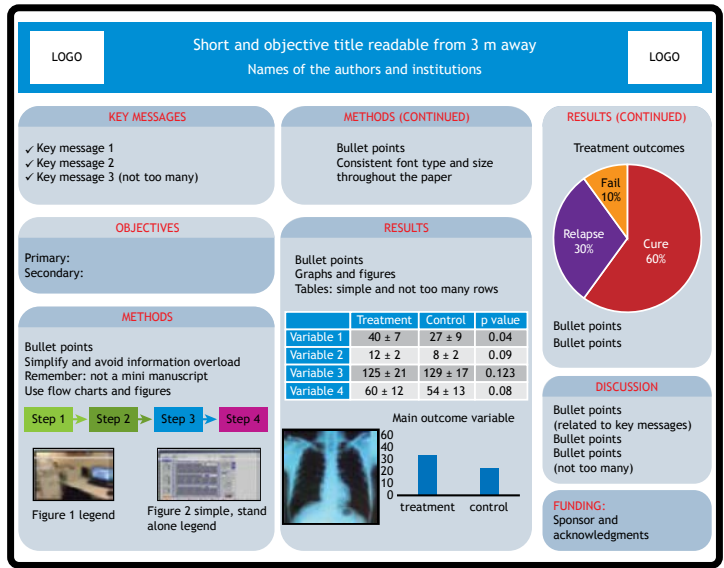

Figure 1. Poster model with examples of headers, figures, graphs, color, and font size. information should be interesting and attractive enough so that attendees will want to come closer, read more, and ask questions.

\section{HOW TO PREPARE YOUR POSTER}

The most important advice is to avoid information overload. Remember: it is not a mini manuscript and attendees have limited time. We recommend that you use bullet points, minimize text, and simplify the language, with easy-to-read phrases. Use the active voice and avoid jargon and acronyms whenever possible. The title should be short and informative. The left upper corner is the first area attendees will look after reading the title and scan it during those 10 seconds, so avoid writing an introduction (remember, it is not a manuscript); instead, start with your key messages (Figure 1). Then state your objectives or research question, so that readers will know what your study is about. When describing your methods, avoid unnecessary details, use bullet points, simplify the text, and use flow charts or figures to illustrate the method process. Results are the most important information you will communicate. Use figures and graphs with legible font, clear axis, and, if possible, with the legend embedded in the graph/figure. Finish your poster with a discussion that aligns with your research question.

Check the conference guidelines for poster orientation and size. Use columns and headers to facilitate reading. Resist the temptation to fill all available space, leave some blank space to make the poster more attractive. It is important to use consistent wording, font, font size, and colors.

\section{KEY MESSAGES}

- A poster is not a mini manuscript; avoid communicating too much information

- Be mindful of using a small font size that is hard to read from a comfortable distance

- Substitute text for figures and graphs whenever possible

- Practice presenting your poster to your friends and colleagues at least five times

- Be prepared, look and act professionally, and make it worth the effort

\section{REFERENCES}

Hamilton CW. At a glance: a stepwise approach to successful poster presentations. Chest. 2008;134(2):457-459. https://doi.org/10.1378/ chest.08-1078

2. Persky AM. Scientific Posters: A Plea from a Conference Attendee. Am J Pharm Educ. 2016;80(10):162. https://doi.org/10.5688/ajpe80455

1. Methods in Epidemiologic, Clinical, and Operations Research-MECOR-program, American Thoracic Society/Asociación Latinoamericana del Tórax, Montevideo, Uruguay.

2. Divisão de Pneumologia, Instituto do Coração, Hospital das Clínicas, Faculdade de Medicina, Universidade de São Paulo, São Paulo (SP) Brasil.

3. Department of Preventive Medicine, Keck School of Medicine, University of Southern California, Los Angeles, CA, USA.

a. (iD http://orcid.org/0000-0001-6548-1384; b. (iD) http://orcid.org/0000-0001-5742-2157 